\title{
Cohabitation group and social skills in elderly women: an experience report
}

\section{Introduction}

Nowadays, it is quite common for the elderly to live alone. It is not good for mental health and it can contributes to increase other pathologies. Despite it happens in all social class, it is most markedly among the poorest. Of note, people who do not have financial resources tend to be more restricted to home isolated from social coexistence what can compromise their social skills.

Social skills are a set of verbal and nonverbal behaviors that enable the individual to respond adequately to their interpersonal demands. ${ }^{1}$ Moreover, social skills present many behaviors such as the ability to defend and expose personal opinions, accept criticism and ask questions. The investigation of this construct in the elderly population has shown to be of great interest mainly for a better development and maintenance of social relations, especially in women, who tend to live longer and increasingly live alone. Furthermore, social skills seem to influence quality of life, aging and mood swings. ${ }^{1}$ Deficits in these social skills can lead to the onset of depressive disorders, or contribute to the maintenance of depression. ${ }^{2}$

Among some characteristics that influence development of social skills in elderly the most relevant are social support network considering friends and family. According to previous studies, institutionalized elderly showed less capacity for assertiveness and self-esteem compared to elderly participants of a cohabitation group. ${ }^{1}$ In this way a group that focus on better performance in social skills have been suggested and demonstrated better results for the elderly. ${ }^{3}$

According to previous studies cohabitation group can improve the quality of life of the elderly population., ${ }^{4,5}$ Researches from south Brazil collected data from elderly who participated from a cohabitation group in public a health service. World Health Organization Quality of Life instrument for older adults (WHOQOL-OLD) and reduced World Health Organization Quality of Life instrument (WHOQOLBREF) were used to describe the quality of life from elderly. As result in this study all participants showed improvements in quality of life. ${ }^{4}$ In addition a study using Flanagan's scale to monitor elderly who have been frequently participated in cohabitation group presented improvements in the quality of life of them, especially for women. ${ }^{5}$

The aim of this study is present an experience report working in a Municipal Health Center in Southern Brazil with elderly women. The present study aims to present an experience report, conducted with elderly people and shows the positive effects on health and social skills of these subjects. It is important to emphasize that this report do not intend to generalize the results, but rather to reflect on how a social intervention can have positive effects on the lives of low-income elderly people. The study contemplated a qualitative psychosocial approach, the focus of the study, since this allows a greater approximation with the daily life and the experiences lived by the subject's themselves ${ }^{6}$ in this case, the group of elderly women.

\section{Case presentation}

During a team meeting, discussing the greater needs of the
Volume 2 Issue 6 - 2017

\author{
Sabrina Chapuis-de-Andrade,' Cristiane Silva \\ Esteves $^{2}$ \\ 'Faculdade de Biociências e de Medicina, Pontifícia Universidade \\ Católica do Rio Grande do Sul, Brazil \\ ${ }^{2}$ Professor at Instituto Federal de Educação do Rio Grande do \\ Sul, Brazil
}

Correspondence: Sabrina Chapuis-de-Andrade, Faculdade de Biociências e de Medicina, Pontifícia Universidade Católica do Rio Grande do Sul,Avenida Ipiranga, Brazil, Tel 90619-900, Email sabrinachapuis@gmail.com

Received: August 27, 2017 | Published: December II, 2017

population that the Municipal Health Center attends, we identified that few actions were offered to the elderly in the territory, especially for women, which are the majority of our patients. In this way, we think about creating a cohabitation group in the public health service, what could contribute to improve the quality of life from them.

The health team did an informal invitation to all women over sixty years old who regularly sought care from the Center to participate from the cohabitation group. We explaining what activities would be carried out in the group and what their purpose would be. The elderly who were interested in participating started to attend the group.

Population was composed of approximately 72 volunteers over sixty years old (mean age $72.9 \pm 8.7$ years), with or without comorbidities, both mental and physical. Most participants were Caucasian $(72.5 \%)$, had at least high school degree (85.1\%) and live alone (60.3\%). All participants live in the same area around the Municipal Health Center located in a poor community of Porto Alegre city, Southern Brazil. This territory has limited access to social activities. There is not a movie theater, for example, near from this community.

We started with activities inside the Health Center. The group encounters were held once a week with duration of forty minutes. A nurse, a doctor, a psychologist and four community health agents conducted activities in this group. Group dynamics, interactive games, stretching exercises and massages on each other were some of the activities performed. Moreover, celebrations and anniversaries were held at the group meetings.

The present study was carried out after two months of the beginning of the meetings of the coexistence group. Only two months after the beginning of activities the group already had the participation of more than seventy elderly. As the Health Center was not so big and we want not to divide the group, once they are having social interaction, we had to look for a bigger place.

For this we counted on the help of the own elders that were articulated and went in search of another place in the community for the accomplishment of the group meetings. About a week and the women even got free the ballroom of one of the community churches. 
With the group happening in this larger place was even easier to carry out the activities of social interaction. Furthermore, we took advantage that there was space and invited other professionals to compose the group. Even people from other communities, mainly women, came to the group to know what we are doing. Besides that, they contributed by proposing new activities.

The main results that we have identified since the implementation of the group were the protagonism of participants in the circumstances that arose throughout the activities. Women who have difficult to talk to health professionals about themselves for example started to express their wishes and feelings more naturally. Because it is a group of women only, they say that it is much easier to talk about health issues or life problems in general and together they find solutions to these issues. Moreover, participants report that they are much happier participating in the group and consider them as part of the family. We realized that the coexistence group made it possible to increase socialization of the elderly, whose social ties are weakened due to their precarious social conditions and due to the aging process itself.

The improvement of the social skills of these elderly women was analyzed through the exchange of experiences and information, through the improvement of the social relations between themselves and with the professionals of the team. The study provided qualitative data regarding the improvement of the participant's socialization, data that were obtained through the participant's reports and the observation of their evolution in communicating. The reports were always positive, showing satisfaction in participating in the group and reporting how much they were feeling better after the meetings began

\section{Discussion}

The cohabitation group experience promoted by a Municipal Health Center in Southern Brazil for elderly women shows that social interaction contributes to the health promotion. Even though the main objective is not to act on the pathologies of the participants, we identified that the group contributed to improve the quality of life from the women.

Other studies have investigated relationship between quality of life and prevalence of pathologies in people with higher or lower level of social interaction. Most studies show that social isolation is related to decreased functional capacity ${ }^{7}$ even causing death. ${ }^{8}$ One study evaluated 46 people for depression associated to social cohabitation. Those diagnosed with depression reported statistically lower levels of social skills. Things like to expose themselves to unknown or new situations, express positive affect and self-esteem, or to control aggression in the face of frustration were much more difficult in this group. Thus, the authors further concluded that depression may be associated to the levels of social skills deficits. ${ }^{2}$

Regarding depressive symptoms, a study from Cuba indicates that elderly women who live with other people is less likely to get sick than women living alone. ${ }^{9}$ Of note, nowadays it is more common women be more independent and to live alone, either by choice or by necessity. However, even living alone, women need to have social support, searched by herself or offered by public services.
On the other hand, a study that evaluated some elderly users of hearing aids regarding reported quality of life did not find association between living alone or accompanied to signs of depression. ${ }^{10}$ However the authors did not consider social support from participants. Even a person who lives alone can have social engagement and perform more activities compared to others. In addition, it is important to consider that living alone can be indicative of favorable financial situation, good health and interaction with family and friends, as opposed to the false idea of helplessness and loneliness.

\section{Conclusion}

Studies about the influence of cohabitation group in the elderly are still scarce in the literature, especially in women. The way each person confronts situations and conducts their interpersonal relationships can interfere with their quality of life. Knowing how these variables relate enables the formation of intervention strategies, aiming to increase the repertoire of social skills in this population.

\section{Acknowledgements}

None.

\section{Conflict of interest}

There is no conflict of interest in composing this manuscript.

\section{References}

1. Carneiro RS, Falcone E, Clark C, et al. Qualidade de vida, apoio social e depressão em idosos: relação com habilidades sociais. Psicologia: reflexão e crítica. 2007;20(2):229-237.

2. Santos FC, Oliveira FEM, Sardinha A. Deficiências em habilidades sociais na depressão: estudo comparativo. Psicologia: teoria e prática. 2012;14(1):183-196

3. Braz AC, Del PZA, Del PA. Assertive social skills training for the elderly. Psicología Conductual. 2011;19(2):373-387.

4. Serbim AK, Figueiredo AEPL. Qualidade de vida de idosos em um grupo de convivência. Scientia medica. 2011;21(4).

5. Galisteu KJ, Facundim SD, Ribeiro R, et al. Qualidade de vida de idosos de um grupo de convivência com a mensuração da escala de Flanagan. Arq Ciênc Saúde. 2006;13(4):209-214.

6. De Souza MMC. O desafio do conhecimento, 11th edn. Pesquisa qualitativa em saúde, Brazil; 2008.

7. Lund R, Laban J, Petersen GL, et al. Loneliness and objectively measured physical capability in middle-aged adults. European Journal of Public Health. 2017.

8. Perissinotto CM, Cenzer IS, Covinsky KE. Loneliness in older persons: a predictor of functional decline and death. Archives of internal medicine. 2012;172(14):1078-1084.

9. Sicotte M, Alvarado BE, León EM, et al. Social networks and depressive symptoms among elderly women and men in Havana, Cuba. Aging and Mental Health. 2008;12(2):193-201.

10. Ferreira AA MR, da Costa VM. Health Promotion in Elderly People: an Experience Report in the Central Region of the City of Rio De Janeiro, MOJ Gerontol Ger. 2017:1(6):1-4 